\title{
Gradient pretilt angle alignment materials with different photosensitivity for tunable polarization-independent self-aligned liquid crystal lens
}

\author{
Veronika S. Bezruchenko SID Student Member ${ }^{1,2}$ (i) | \\ Alexander A. Muravsky SID Member ${ }^{1,2}$ (D) | Anatoli A. Murauski SID Member | \\ Alexander I. Stankevich ${ }^{2}$ | Uladzimir V. Mahilny²
}

\author{
${ }^{1}$ Institute of Chemistry of New Materials, \\ NAS of Belarus, F. Skorina, 36, Minsk, \\ 220141, Belarus \\ ${ }^{2}$ Physical Department, Belarusian State \\ University, Minsk, Belarus

\section{Correspondence} \\ V.S. Bezruchenko, Institute of Chemistry \\ of New Materials, NAS of Belarus, \\ F. Skoriny St. 36, 220141, Minsk, Belarus. \\ Email: veronika.bezruchenko@gmail.com
}

\begin{abstract}
Alignment of benzaldehyde materials with different photosensitivity thresholds, capable of changing the pretilt angles of nematic liquid crystal (LC) from $90^{\circ}$ to $0^{\circ}$ in a controlled manner under UV-B exposure, has been developed. Inhomogeneous exposure of uniform rubbed alignment layers allows the formation of a refractive index gradient inside the LC cell. The concept of tunable polarizationindependent self-aligned LC lens based on gradient pretilt angle alignment materials with different photosensitivity is demonstrated. Self-alignment of two polarization-dependent sub-lens is achieved due to a single exposure act of two alignment layers, which are located on the same piece of glass on both sides, forming one common optical axis for a polarization-independent LC lens. The sublens cells have uniform cell gap and are independently controlled using lowvoltage driving. Devices based on gradient benzaldehyde alignment materials can be used in many modern optical and photonic devices.
\end{abstract}

\section{KEYWOR D S}

gradient alignment materials, polarization-independent LC lens

\section{1 | INTRODUCTION}

The alignment material for liquid crystal (LC) with the ability to set the pretilt angle gradient allows the implementation of various passive or active LC devices and optical elements such as diffraction gratings, lenses, waveguides, and others. ${ }^{1}$ Various complexity structural implementations of the tunable LC lenses have been reported, ${ }^{2-5}$ while one of the most technological fabrication methods is based on the application of gradient alignment materials. ${ }^{6-8}$ This method will improve a number of disadvantages inherent in LC lenses ${ }^{9,10}$ : a large number of defects, limiting the maximum and minimum diameter; the necessity of thick devices for high optical power; the derived response time of thick devices; the high voltage required to change the refractive index; the polarization dependency of LC lenses; and others.

Alignment materials with a variable pretilt angle are subject to high requirements: the high anchoring energy, pretilt angles reproducibility, defect-free orientation, low control voltages to change the refractive index, etc. All these requirements are fulfilled via the application of gradient alignment layers for the creation of tunable LC lenses, ${ }^{6,11,12}$ based on photosensitive alignment materials with the following properties:

- Low alignment material baking temperature $70-90^{\circ} \mathrm{C}$

- Standard rubbing alignment process 
- Increased anchoring energy of the alignment layer

- UV-B sensitivity in the range of 300-330 nm

- Reproducible monotonic change of the pretilt angle from $90^{\circ}$ to $0^{\circ}$ under non-polarized UV-B exposure

- Adjustable photosensitivity threshold of the alignment layer predetermined by monomers ratio in the course of copolymerization

- No absorption in the visible spectral range

- High photostability of photoalignment properties.

UV and thermal stability of benzaldehyde alignment materials have been checked by Mahilny et $\mathrm{al}^{13}$ and showed good results.

Common LC lenses are polarization-dependent, focusing the incident rays with an electric field corresponding to the alignment direction of the LC lens, and rays with orthogonal polarization pass through it without changes. ${ }^{14}$ Using a polarizer in front of the LC lens allows us to select the appropriate rays with the necessary polarization and improve the characteristics of the LC device. However, this approach sacrifices brightness and reduces the efficiency of LC lenses application in optical devices; therefore, the most promising direction for the development of LC lenses is the creation of polarization-independent devices. Various methods for manufacturing polarization-independent LC lenses are proposed. ${ }^{15-17}$ A polarization-independent LC lens can also be formed when the LC is oriented on the surface of

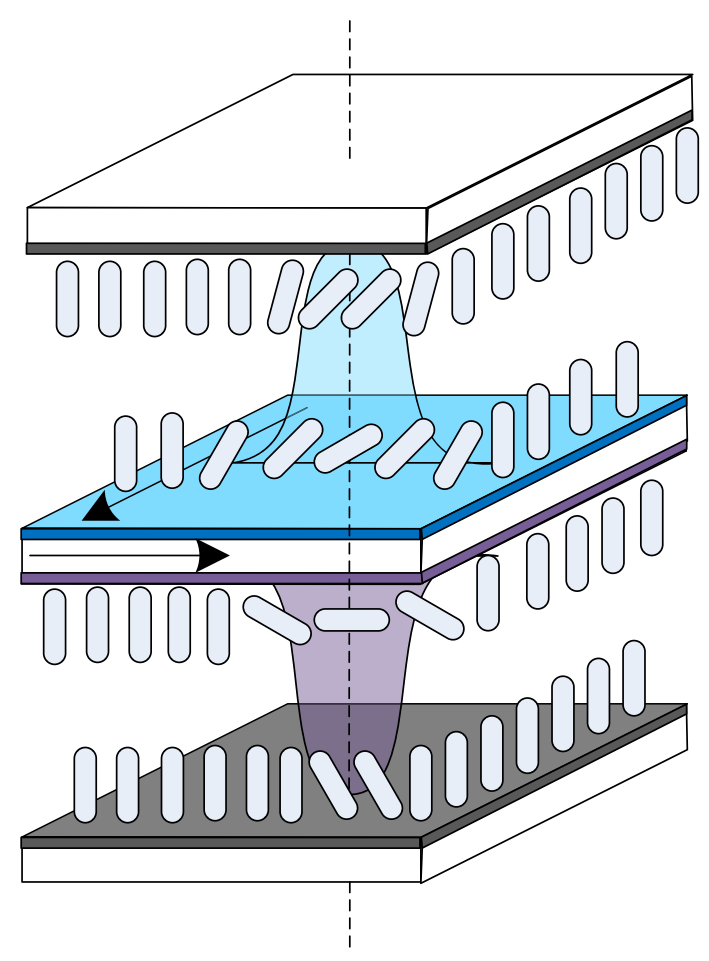

FI G URE 1 Polarization-independent LC lenses structure the substrates in the orthogonal direction; in this case, the near-surface layer of the LC acts as a working element. ${ }^{17}$ The combination of two round polarizationdependent LC lenses with a mutually perpendicular orientation direction is the technique, which raises the problem of the mutual positioning of the two lenses. ${ }^{14,18}$ The resulting image from such lenses will consist of two images formed by each lens independently, and when the two lenses are made independently, an offset always takes place. The mutual exact combination of two lenses, or else self-alignment, is the solution to this problem. Development and application of gradient alignment materials with different photosensitivity for getting polarization-independent LC lens, consisting of two independently tunable polarization-dependent sub-lenses, located in one tunable LC cell, and consisting of three glass substrates (Figure 1), is the aim of this work. ${ }^{19}$

\section{2 | EXPERIMENT}

\section{1 | Gradient alignment materials with different photosensitivity thresholds}

We investigated LC director inclination on the gradient pretilt angle alignment materials (GPAAM) comprising $40 \%_{\text {mol }}$ (GPAAM1) and $25 \%_{\text {mol }}$ (GPAAM2) of vertical alignment groups in the course of UV irradiation of alignment layers. Glass substrates were coated with thin polymer layers $(45-80 \mathrm{~nm})$ from a $2 \%$ solution of GPAAM in butyl acetate by the rod-coating method ${ }^{20}$ (or draw-bar coating method ${ }^{21}$ ). After drying at $70^{\circ}$ for $5 \mathrm{~min}$, the layers were uniformly rubbed with a cloth and exposed to unpolarized UV-B light of T8-UVC-15 W-G13 (AerVita, Russia) fluorescent tube lamp under the intensity of $4 \mathrm{~mW} / \mathrm{cm}^{2}$. The surface of GPAAM layer was divided into several areas that were irradiated for various time intervals. The substrates were assembled in antiparallel LC cells with $20 \mu \mathrm{m}$ cell gap. The cells were filled with LC E7 $\left(\mathrm{n}_{\mathrm{o}}=1.61, \mathrm{n}_{\mathrm{e}}=1.83, \Delta \mathrm{n}=0.22, \lambda=550 \mathrm{~nm}\right.$, $\mathrm{t}=20^{\circ}$ ) and hermetically sealed. The pretilt angles were measured by the cell rotating method between crossed polarizers $^{22}$ at the He-Ne laser wavelength of $0.633 \mu \mathrm{m}$.

\section{2 | Self-aligned polarization- independent LC lens design and fabrication}

Self-aligned polarization-independent LC lens based on GPAAM with different photosensitivity consists of three substrates arranged in the form of a sandwich. A layer of 40-80 $\mathrm{nm}$ of vertical alignment material was spin-coated 
from $1 \%_{\text {mass }}$ solution in butyl acetate at 3000 Rotation Per Minute (RPM) for $60 \mathrm{~s}$ on two outer 1-mm-thick ITO glass substrates, baked at $90^{\circ} \mathrm{C}$ on a hot plate for $5 \mathrm{~min}$, and then irradiated with uniform unpolarized UV-B exposure for $5 \mathrm{~min}$.

GPAAM 1 and GPAAM 2 were deposited on both sides of the Indium Tin Oxide (ITO) glass substrate, located in the middle of the sandwich structure of the LC cell. Double-sided ITO-coated glass substrate was used as the middle substrate of the LC cell (Figure 2).

A $1 \%$ mass solution of GPAAM1 polymer in butyl acetate was spin-coated on one side of a glass substrate at $3000 \mathrm{RPM}$ for $60 \mathrm{~s}$. The substrate was baked at $90^{\circ} \mathrm{C}$ on a hot plate for $5 \mathrm{~min}$. Then, a $1 \%_{\text {mass }}$ solution of GPAAM2 polymer in butyl acetate was spin-coated on another side of a glass substrate at 3000 RPM for $60 \mathrm{~s}$. The substrate was again baked at $90^{\circ} \mathrm{C}$ on a hot plate for $5 \mathrm{~min}$. The alignment layers were rubbed in orthogonal directions with a cloth as in the standard alignment layer rubbing process and exposed via a "round hole" photomask with UV lamp radiation. During the irradiation, a centrosymmetric exposure field with a bell-shaped distribution of illumination was formed. ${ }^{23}$ Such exposure conditions provide a light intensity distribution required for the induction of the LC lens pretilt angle gradient. The spacing between the photomask and the alignment layer was $0.5 \mathrm{~mm}$. The diameter of the round hole and the exposure time were $1,5 \mathrm{~mm}$ and $32 \mathrm{~min}$, correspondingly. The cell gap of $20 \mu \mathrm{m}$ was fixed by fiber spacers. Finally, the cell was filled with LC E7 and hermetically sealed.
FIG URE 2 Process flow of self-aligned polarization-independent LC lenses fabrication

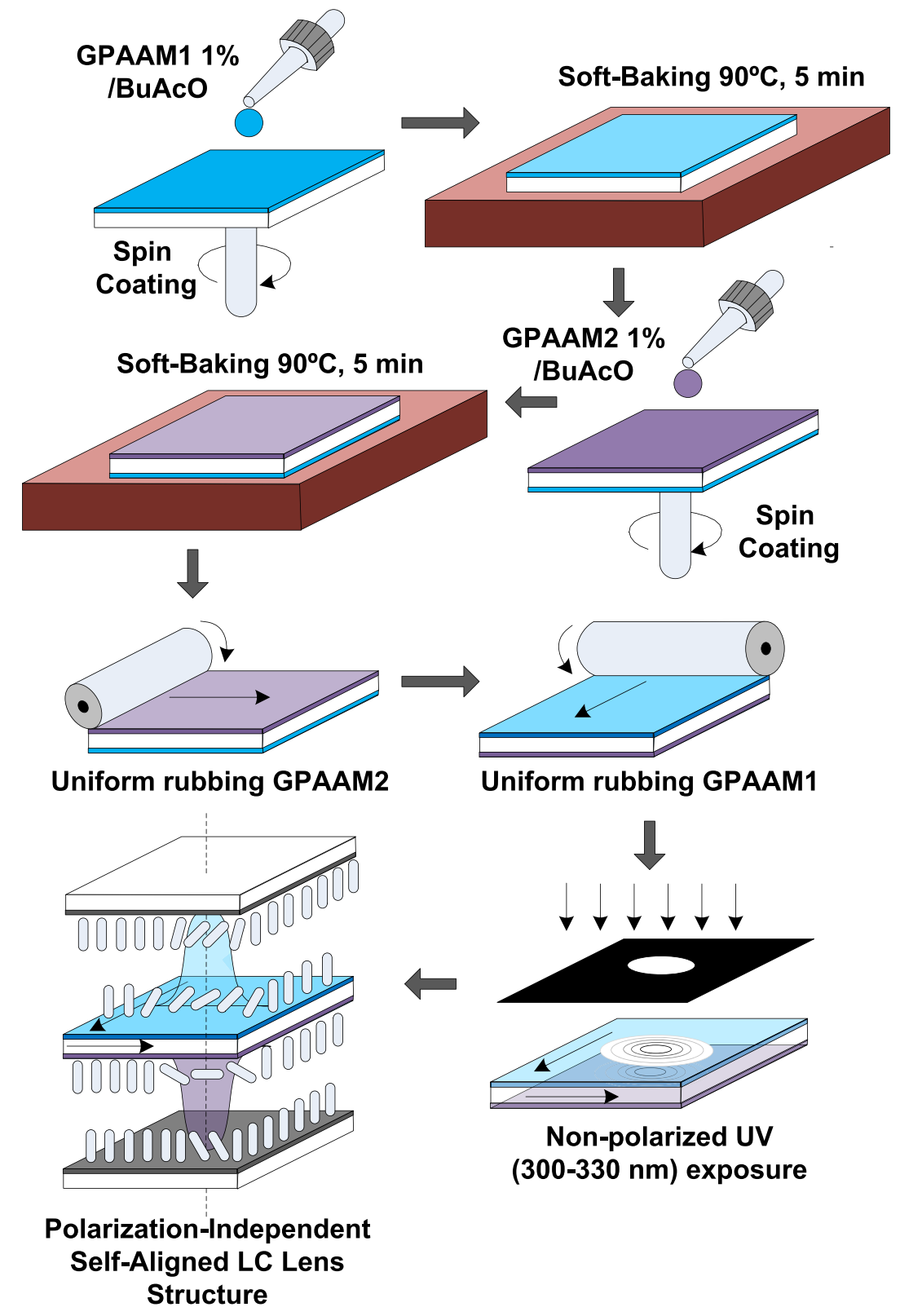

Soft-Baking $90^{\circ} \mathrm{C}, 5 \mathrm{~min}$ IBuAcO

niform rubbing GPAAM2

Non-polarized UV (300-330 nm) exposure
Polarization-Independent

Structure 


\section{3 | RESULTS AND DISCUSSION}

The pretilt angles of the GPAAM1 and GPAAM2 layers on the UV exposure time under uniform irradiation were measured and applied for LC lens fabrication. ${ }^{6}$ The gradual decrease of sensitivity thresholds from vertical to the planar state is demonstrated in Figure 3 for GPAAM2 and GPAAM1. In the first case, the decrease develops in the approximate range $0.24-1.92 \mathrm{~J} / \mathrm{cm}^{2}$; in the second case the range is shifted to $1.92-7.68 \mathrm{~J} / \mathrm{cm}^{2}$.

The experimental uncertainties in the values of the pretilt angles from the exposure dose are estimated to vary from $0.5^{\circ}$ to $2^{\circ}$.

In order to be able to apply a voltage potential to both cells of the polarization-independent LC lens, we used double-sided ITO-coated glass substrate of $0.1 \mathrm{~mm}$ thickness. Such a glass substrate has transmittance in the
UV-B region (300-330 nm) about 10\% (Figure 4). That means that alignment material on the bottom side of the substrate receives 10 times smaller light dose than the material on the top side.

However, the shape of the light intensity distribution that induces lens pretilt angle gradient of the alignment layer remains the same, as well as the mutual alignment of the centers of the light spots at the top and bottom sides of the double-sided ITO glass substrate. It gives the requirement for the sensitivity of the alignment materials deposited on the top and bottom sides of the intermediate substrate: on the bottom side material of 10-fold higher sensitivity is required (Figure 5). Accordingly, in Figure 3 there is rough compliance of GPAAM1 and GPAAM2 photosensitivity with this condition.

Exposure of two layers of alignment materials in one step provides self-alignment of the optical axes of two
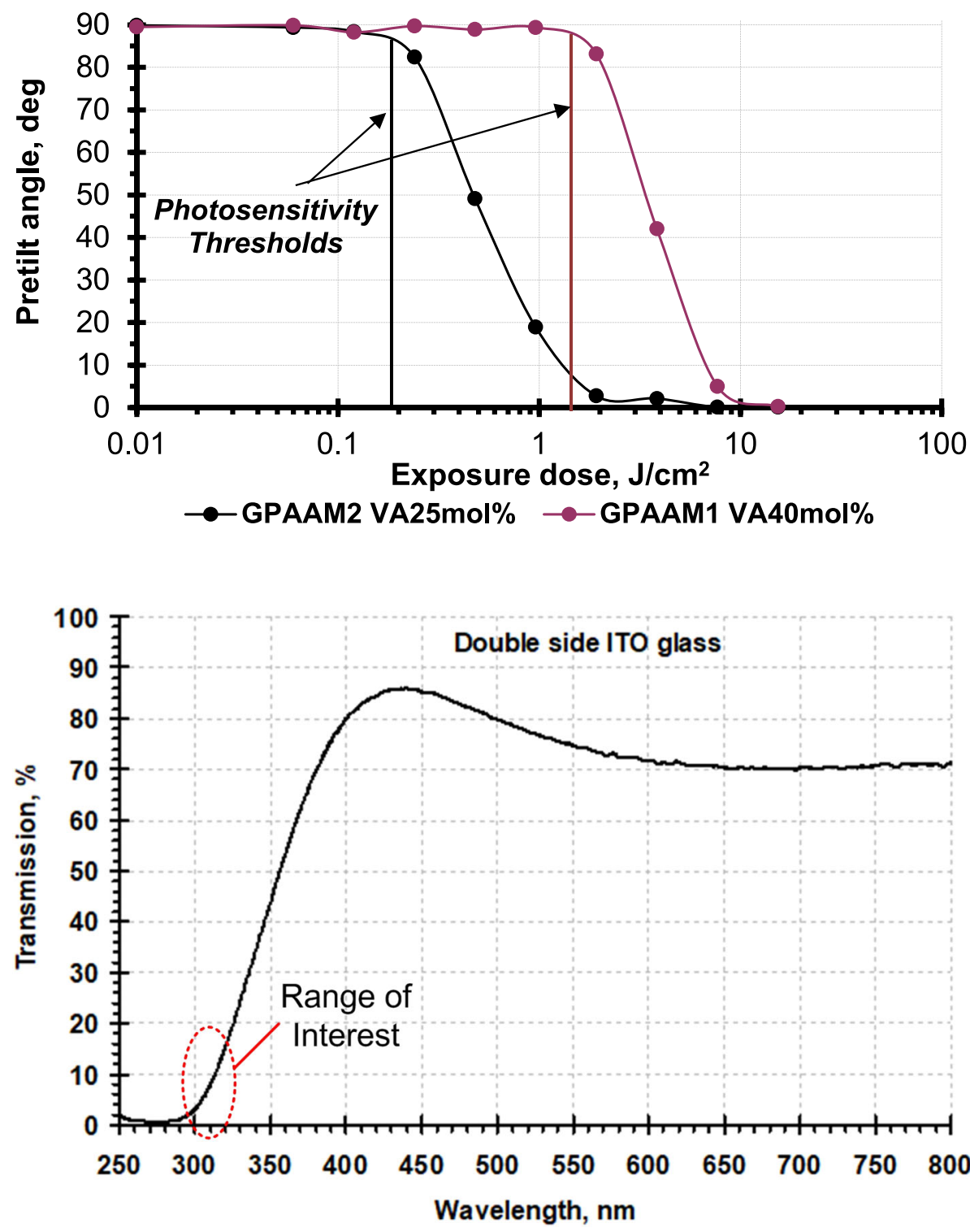

FIG URE 3 The pretilt angle dependences on UV light exposure dose for GPAAM1 and GPAAM2
FIG URE 4 The transmission spectrum of double-sided ITO glass substrate of $0.1 \mathrm{~mm}$ thickness 
F I G U RE 5 Self-aligning exposure scheme of the alignment layers on the intermediate substrate

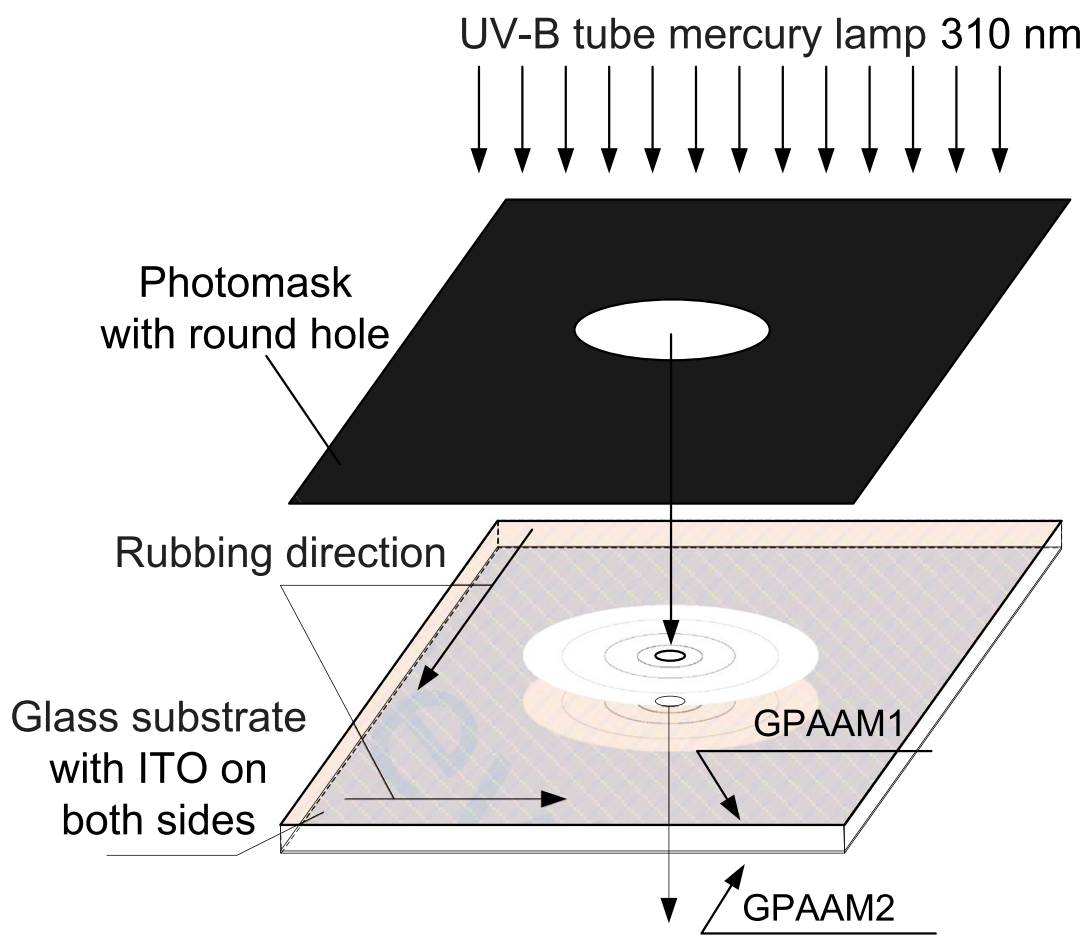

lenses formed due to the gradient of the pretilt angle on the upper and lower sides of the substrate and, therefore, the common optical axis of both cells for a polarizationindependent LC lens.

The fabricated LC lens comprises two sub-lenses, which have two electrodes each at top and bottom substrates, and can be controlled independently. The axes of the sub-lenses are orthogonal to each other. The exact identity of pretilt angle distribution and the same thickness of the sub-lenses should result in mutual birefringence compensation. In that case, the phase gradient of the polarization-independent LC lens is not observed in the polarization microscope when the lens axes are at $45^{\circ}$ to the crossed axes of the polarizer and analyzer. Actually, in our experiment optical transmission of the system measured with spectrometer Ocean Optics HR4000CG UV-NIR (USA) within the lens was constant in the limits of $5 \%$. This confirms the high degree of
F I G URE 6 Direct measurements of LC sublens optical phase distribution for applied voltage levels of $0,3,5$, and $10 \mathrm{~V}$

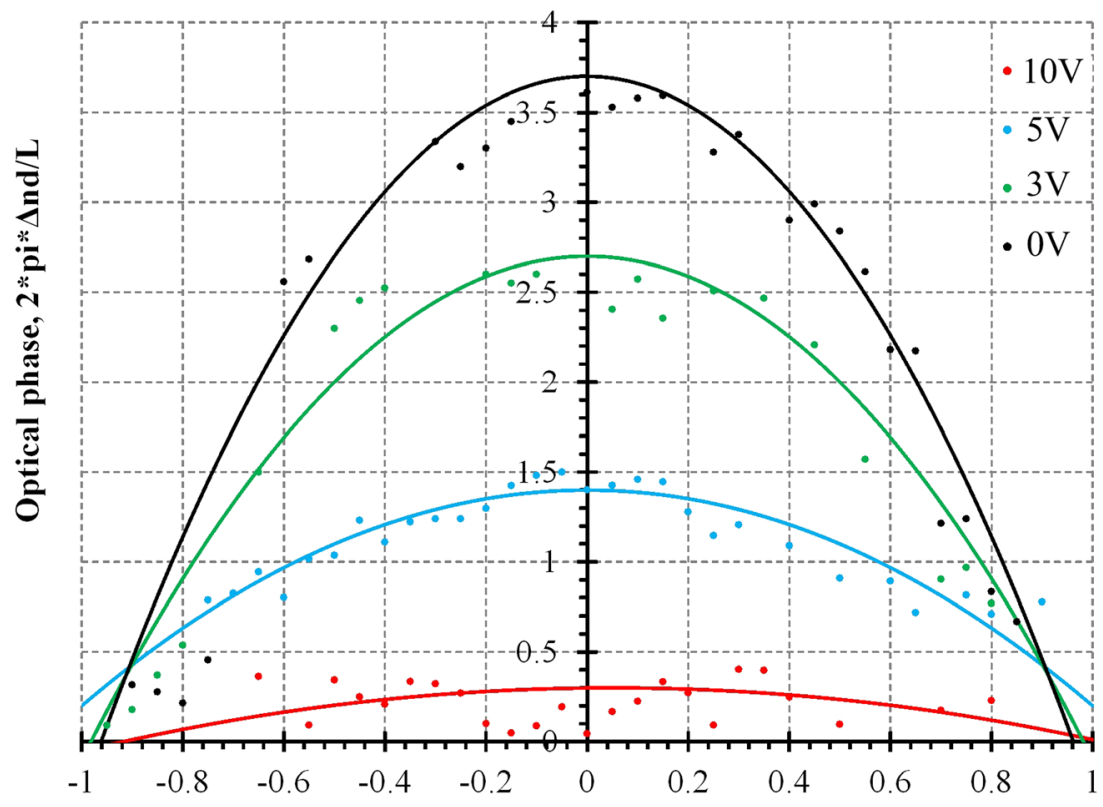

Distance from LC lens center, mm 
similarity of phase distributions for both sub-lenses under zero voltage.

To observe and analyze optical phase distribution, independent control of the LC lens sample was used. First, a high voltage level of $15 \mathrm{~V}$ was applied to the top sub-lens to turn the lens off by switching the LC into a uniform vertical orientation. Then different voltage levels of 0 to $10 \mathrm{~V}$ were applied to the bottom one. As shown in Figure $610 \mathrm{~V}$ is sufficient to transfer the LC of the sublens into a vertical state and almost completely transform it into a uniform phase plate, which corresponds to the lens with infinite focal length. We conclude that the operating voltage levels of the obtained LC lens for tunable focal length are below $10 \mathrm{~V}$.

Optical phase measurement accuracy was better than 0.1

The diameter of the developed LC lens is voltage dependent and unlike a common lens is not a constant. Thus, LC lens diameter is about $\sim 2.0 \mathrm{~mm}$ for $10 \mathrm{~V}$, and it increases to $2.5 \mathrm{~mm}$ for $3 \mathrm{~V}$ of applied voltage level. It is the specific property of the pretilt angle gradient LC lens fabricated by the developed exposure technique with a round hole photomask. Probably, it is related to the elastic properties of LC and its interaction with gradient alignment material.

The UV lamp spectrum affects the reproducibility of the phase profile values in Figure 6. It has been noticed that significant light interference occurs at the glass thickness on using low-pressure mercury lamp or laser "coherent" radiation, which affects the actual localized pretilt angle value. Thus, non-uniform pretilt angle gradient takes place inside the cell, which in our case led to the values spread of the LC lens phase profile (Figure 6). Utilization of wide bandwidth noncoherent LED light sources is one of the possible solutions.

Key features of the polarization-independent LC lens:

- One LC cell with three substrates is applied;

- the photosensitive layers at the intermediate substrate are exposed simultaneously in one step to provide selfalignment of LC gradient structures;

- independent control of the sub-lenses can be used to adjust their focusing LC distributions;

- low level of control voltages.

\section{4 | CONCLUSIONS}

GPAAMs with different photosensitivity threshold and their application for self-aligned polarizationindependent LC lens are presented. The polarizationindependent LC lens based on GPAAMs consists of two polarization-dependent LC sub-lenses both with a uniform cell gap. Self-alignment is realized through simultaneous exposure of alignment layers with different photosensitivity coated on both sides of the double-sided ITO glass substrate. Polarization independence is achieved by the perpendicular crossing of the azimuthal alignment direction of the polarization-dependent LC lenses. These LC sub-lenses are controlled in parallel with low alternating current voltage levels $0-12 \mathrm{~V}$. The materials were successfully applied for polarizationindependent self-aligned LC lens fabrication. ${ }^{19}$

\section{ORCID}

Veronika S. Bezruchenko (10) https://orcid.org/0000-00025505-4538

Alexander A. Muravsky (D) https://orcid.org/0000-00030652-7391

\section{REFERENCES}

1. Chigrinov VG. Liquid crystal photonics: engineering tools, techniques and tables. New York: Nova Science Publishers; 2014.

2. Algorri JF, Bennis N, Urruchi V, Morawiak P, SánchezPena JM, Jaroszewicz LR. Tunable liquid crystal multifocal microlens array. Sci Rep. 2017;7(1):17318.

3. Cheng $\mathrm{CC}$, Chang $\mathrm{CA}$, Liu $\mathrm{CH}$, Yeh JA. A tunable liquidcrystal microlens with hybrid alignment. J Opt A: Pure Appl Opt. 2006;8(7):S365-S369.

4. Xu S, Li Y, Liu Y, Sun J, Ren H, Wu ST. Fast-response liquid crystal microlens. Micromachines. 2014;5(2):300-324.

5. Beeckman J, Yang TH, Nys I, George JP, Lin TH, Neyts K. Multi-electrode tunable liquid crystal lenses with one lithography step. Opt Lett. 2018;43(2):271-274.

6. Bezruchenko VS, Muravsky AA, Murauski AA, Stankevich AI, Mahilny UV. Tunable liquid crystal lens based on pretilt angle gradient alignment. Mol Cryst Liq Cryst. 2016;626(1):222-228.

7. Tseng MC, Fan F, Lee CY, Murauski A, Chigrinov V, Kwok HS. Tunable lens by spatially varying liquid crystal pretilt angles. J Appl Phys. 2011;109(8):083109.

8. Fan F, Srivastava AK, Du T, Tseng MC, Chigrinov V, Kwok HS. Low voltage tunable liquid crystal lens. Opt Lett. 2013;38(20):4116-4119.

9. Algorri J, Urruchi V, García-Cámara B, Sánchez-Pena J. Liquid crystal microlenses for autostereoscopic displays. Dent Mater. 2016;9(1):36.

10. Algorri JF, Zografopoulos DC, Urruchi V, Sánchez-Pena JM. Recent advances in adaptive liquid crystal lenses. Crystals. 2019;9(5):272.

11. Bezruchenko VS, Muravsky AA, Murauski AA, Stankevich AI, Mahilny UV. Alignment materials with controllable anchoring energy. J Soc Inf Disp. 2018;26(9):561-566.

12. Bezruchenko VS, Mahilny UV, Stankevich AI, Muravsky AA, Murauski AA. New photo-crosslinkable benzaldehyde polymers for creating liquid crystal lenses. J Appl Spectrosc. 2018; 85(4):704-709.

13. Mahilny UV, Stankevich AI, Muravsky AA, Murauski AA. Novel polymer as liquid crystal alignment material for plastic substrates. J Phys D Appl Phys. 2009;42(7):075303. 
14. Xin $Z$, Tong Q, Lei $Y$, et al. An electrically tunable polarization and polarization-independent liquid-crystal microlens array for imaging applications. Aust J Optom. 2017;19(9):095602.

15. Lin Y-H, Yu-Shih T. A polarization independent liquid crystal phase modulation adopting surface pinning effect of polymer dispersed liquid crystals. J Appl Phys. 2011;110(11):114516.

16. Lin YH, Chen HS, Lin HC, Tsou YS, Hsu HK, Li WY. Polarizer-free and fast response microlens arrays using polymer-stabilized blue phase liquid crystals. Appl Phys Lett. 2010;96(11):113505.

17. Wahle M, Snow B, Sargent J, Jones JC. Embossing reactive mesogens: A facile approach to polarisation-independent liquid crystal devices. Adv Opt Mat. 2019;7(2):1801261.

18. Lin YH, Chen HS. Electrically tunable-focusing and polarizerfree liquid crystal lenses for ophthalmic applications. Opt Express. 2013;21(8):9428-9436.

19. Al-Saud TSM, Altamimi RM, Agabekov VE, Muravsky AA, Murauski AA, Biazruchanka VS. Alignment material for liquid crystal lens and liquid crystal lens system. Patent US 9513510 B1. Washington, DC: U.S. Patent and Trademark Office; 2016.

20. Muravsky A, Murauski A, Mikulich V, Agabekov V. The influence of deposition conditions on the quality of the photoalignment films of azo dye with intermolecular bonds. Bulletin of Moscow Region State University. Series: Phys-Mathe. 2013;1: 48-50.

21. Mulligan CJ, Nicolaidis NC, Vaughan B, Zhou X, Belcher WJ, Dastoor PC. Fabrication of large-area organic photovoltaics using a draw-Bar coating technique. MRS Online Proc Lib Arc. 2013;1529.

22. Cuminal MP, Brunet M. A technique for measurement of pretilt angles arising from alignment layers. Liq Cryst. 1997;22(2):185-192.

23. Bezruchenko VS, Mahilny UV, Stankevich AI, Muravsky AA, Muravsky AA, Kukhta IN. The formation of the centrosymmetric distributions of light intensity for exposure of photosensitive alignment layers of LC lenses. J Belarusian State Univ Phy. 2017;3:12-19.

\section{AUTHOR BIOGRAPHIES}

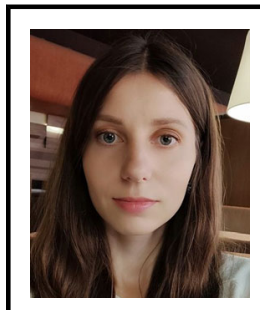

V.S. Bezruchenko, Associate Research Fellow. Graduated from the Physics Department of Belarusian State University (BSU), Belarus, in 2012. She received her MSc (2013) degree in Researchers Training Institute (RTI) NAS Belarus, Belarus. Currently, she is a PhD student at the Belarusian State University (BSU), Belarus. From 2011 till present she works in the Laboratory of Materials and Technologies of LC devices of the Institute of Chemistry of New Materials (IChNM) NAS Belarus, Belarus, in the position of associate research fellow. Her main research interests are anisotropic optical materials, alignment materials, and LCD technologies.

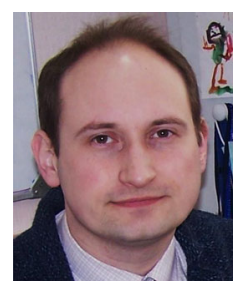

A.A. Muravsky, Head of MTLCD lab. Graduated from the Physics Faculty of Belarusian State University (BSU), Belarus, in 2005. He received his $\mathrm{PhD}$ (2008) degree in Electrical and Electronic Engineering at Hong Kong University of Science and Technology (HKUST), Hong Kong. Since 2009 till present he is the Head of "Materials and Technologies of LC Devices" laboratory at the Institute of Chemistry of New Materials (IChNM) NAS Belarus, Belarus. Since 2020 till present he is associate professor at the Physics Department of BSU. His main research interests are liquid crystal technologies, patterned alignment, anisotropic materials for photonic, organic electronics, and display devices. He is a member of the Society for Information Display (SID).

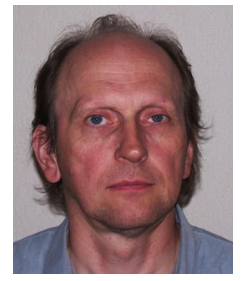

A.A. Murauski, Leader Researcher. Graduated from the Physics Department of Belarusian State University (BSU), Belarus, in 1981. He received his $\mathrm{PhD}$ (2007) degree in Electrical and Electronic Engineering at Hong Kong University of Science and Technology (HKUST), Hong Kong. From 1981 till 2005 he worked at the Institute of Applied Physical Problems, Belarus. From 2005 till 2010 he was a visiting scholar in Center for Display Research, HKUST. Currently he is the Leader Researcher of laboratory at the Institute of Chemistry of New Materials (IChNM) NAS Belarus, Belarus. His research area includes the investigation of electro-optical effects in LC and the R\&D of LCD devices. He develops different methods for investigating the alignment properties of LCD materials. He is a member of the SID.

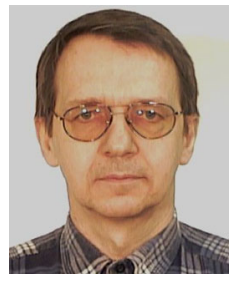

A.I. Stankevich, Senior Researcher. Graduated from the Chemical Department of Belarusian State University (BSU), Belarus, in 1975 and received from it his $\mathrm{PhD}$ degree in Organic Chemistry in 1984. From 1975 to 2015 he carried out research work on synthesis and investigation of organic photosensitive media at the Physics Department of the BSU. His research interests are photosensitive monomers and polymeric materials for LCD technologies. 


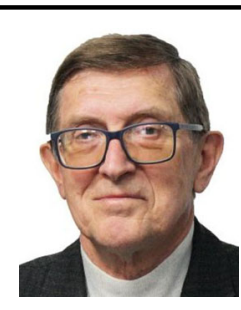

U.V. Mahilny, Professor. He graduated from the Physics Department of Belarusian State University (BSU), Belarus in 1972. He received from BSU his $\mathrm{PhD}$ in Optics in 1982 and DSc in 1998. From 1972 to 1982 he carried out researches on organic photosensitive media at various departments of BSU. Then he has been the associate professor (from 1984 till 1999) and full professor (from 1999 till present) at the Physics Department of BSU. His research interests include investigation and development of photosensitive polymeric materials for technological applications.

How to cite this article: Bezruchenko VS, Muravsky AA, Murauski AA, Stankevich AI, Mahilny UV. Gradient pretilt angle alignment materials with different photosensitivity for tunable polarization-independent self-aligned liquid crystal lens. J Soc Inf Display. 2021;1-8. https://doi.org/10.1002/jsid.990 